\title{
Identification of surface functional group on activated carbon from waste sago
}

\author{
Octolia Togibasa ${ }^{1}$, Yane Oktovina Ansanay ${ }^{2}$, Khaeriah Dahlan $^{3}$, Maya Erari ${ }^{4}$ \\ 1,3,4 Department of Physics, Physics Study Program, Universitas Cenderawasih, Jayapura, Papua \\ Indonesia, 99351 \\ ${ }^{2}$ Department of Physics, Geophysics Study Program, Universitas Cenderawasih, Jayapura, \\ Papua Indonesia, 99351 \\ E-mail: ${ }^{1}$ octolia@gmail.com
}

Received 25 January 2021, Revised 12 March 2021, Published 30 March 2021

\begin{abstract}
Activated carbon is a powerful adsorption material which mainly used as pollutants adsorption. The adsorption properties own derived from the main functional groups or chemical atoms derived from the activation processes. In this study, the activated carbon was prepared from waste sago and activated using two different chemicals activation agents called phosphoric acid and potassium hydroxide. The aim of this study was to identify the surface functional group on waste sago activated carbon produced. The results showed that activated carbon with phosphoric acid activator contained $\mathrm{OH}, \mathrm{C}=\mathrm{C}, \mathrm{CO}$ and $\mathrm{CH}$ functional groups, while activated carbon with potassium hydroxide activator contained $\mathrm{O}-\mathrm{H}, \mathrm{C} \equiv \mathrm{C}, \mathrm{C}=\mathrm{C}, \mathrm{C}-\mathrm{O}$ and $\mathrm{C}-\mathrm{H}$ functional groups. These results lead to support the recommendations for the development of the application of waste sago activated carbon made as adsorbents in the purification of lead (II) and cadmium (II) wastewater.
\end{abstract}

Keyword: activated carbon, waste sago, functional group, pollutants adsorption, phosphoric acid, potassium hydroxide

\section{Introduction}

Activated carbon, known also as activated charcoal, is associated with a carbon-based material that have developed high surface area $\left(>1000 \mathrm{~m}^{2} / \mathrm{g}\right)$, controllable pore structure, and a wide spectrum of oxygenated functional groups (García, 2018). Activated carbon owning powerful adsorption properties that lead to several applications in pollutants adsorption, for instance the uses of water treatment (Bhatnagar et al., 2013), gas separation (Dantas et al., 2011), and dye removal from industrial wastewater (Foo \& Hameed, 2010). Recent progress also showed that activated carbon effectively potential use in the process of biodiesel production (Narowska et al., 2019), producing glucose from biomass (Ansanay et al., 2021) and electric double layer capacitor active materials for supercapacitor application (Faraji \& Ani, 2015).

Moreover, activated carbon has become favorable due to its low-cost raw material, namely lignocellulosic biomass, which may be found in many kinds of waste materials 
(Nor et al., 2013). Waste tea (Yagmur et al., 2008), waste apricot (Başar, 2006), waste walnut shell (Kim et al., 2001), even waste newspaper (Okada et al., 2001) and waste rubber tire (Gupta et al., 2014), and many more were used as precursor materials. However, the selection of the precursor for the development of low-cost activated carbons should be preferable freely available, inexpensive, and nonhazardous for nature. Note that precursor selection also highly determines the surface, structural and textural characteristics (García, 2018).

Generation of activated carbon reported were reported in several kind of process, such as pyrolysis process (Zhu et al., 2009), physical and chemical activation process (Bae et al., 2014; Ioannidou, 2007) and carbonization and steam/thermal activation (Alvarez et al., 2014). Nevertheless, simple thermal activation in nitrogen atmosphere (Zhao et al., 2015) and microwave radiation (Foo \& Hameed, 2012) have been proposed as effective methods to obtain activated carbon. In addition, the use of combined chemical and physical activation is also an alternative to increase the textural features and create hierarchical porosity.

The unique adsorption properties of activated carbon came from the main functional groups named carboxyl, carbonyl, phenol, lactone and quinone. Oxygen, hydrogen, Sulphur and nitrogen are also present in the form of functional groups or chemical atoms, which are derived mainly from activation processes (Bhatnagar et al., 2013). Therefore, the identification of its functional group is one of the important characteristics in activated carbon materials. Identification of the surface functionalities has been usually performed by infrared spectroscopy particularly in the infrared region of the electromagnetic spectrum (García, 2018).

In this study, the activated carbon was prepared from waste sago, as an endemic plant in Southeastern Asia and a very commonly found as local food in Papua and Maluku, however the waste generated has not been used optimally. Moreover, waste sago chosen as precursor materials due to its lignocellulose content (Allo et al., 2019). Waste sago carbon were activated using two different chemical activations called phosphoric acid $\left(\mathrm{H}_{3} \mathrm{PO}_{4}\right)$ and potassium hydroxide $(\mathrm{KOH})$. The purpose of this study was to identify the surface functional groups on activated carbon waste sago that activated in acid and base activating agents selected.

\section{Materials and Methods}

\subsection{Materials and Apparatus}

Waste sago as the precursor material was obtained from the local traditional production of Maribu Village, Jayapura Regency, Papua Province. Activating agents used were base $\mathrm{KOH}$ solution and acid $\mathrm{H}_{3} \mathrm{PO}_{4}$ solution. Other supporting materials were $\mathrm{NaOH} 10 \mathrm{M}$, distilled water, universal test paper, and filter paper. Test sieve and magnetic stirrer were applied in activating process, while the PerkinElmer Spectrum IR 10.6.1 Fouriertransform infrared (FTIR) spectroscopy was used to investigate the functional groups contained in the activated carbon materials. 


\subsection{Activation Process}

The raw material of waste sago was washed and then dried naturally under the sunlight for 3 days, then followed by drying in an oven for 2 hours at $110^{\circ} \mathrm{C}$. This step was aimed to remove dust and other impurities from the precursors. The dried waste sago was carbonized using an oven for two hours at $300^{\circ} \mathrm{C}$. After carbonization, the resulting carbon was resized and sieved into particular size. Before activation process, silica extraction was performed by mixing the carbon powder with $\mathrm{NaOH}$ solution to remove the high silica content in waste sago carbon. As this study used the same method, the details of silica extraction process can be found in previous report (Allo et al., 2019). The prepared carbon was divided into two parts to be used for two different activating agents.

\subsubsection{Activation using acid activating agent $\mathrm{H}_{3} \mathrm{PO}_{4}$}

The prepared carbon of waste sago was impregnated by certain amount of $85 \mathrm{wt} . \%$ concentration phosphoric acid. The amount of $\mathrm{H}_{3} \mathrm{PO}_{4}$ solution used was adjusted to give a certain impregnation ratio (weight of activating agent/weight of raw material) of 6:1, 9:1, dan 12:1. The impregnated material are filtered and put into a porcelain cup followed with heating process in the furnace at $500{ }^{\circ} \mathrm{C}$ for 2 hours. The activated carbon of waste sago was repeatedly washed with warm distilled water $\left(70^{\circ} \mathrm{C}\right)$ until constant $\mathrm{pH}$ solution of 7 was reached. Finally, the activated carbon was dried in an oven at $110^{\circ} \mathrm{C}$ for $24 \mathrm{~h}$.

\subsubsection{Activation using base activating agent $\mathrm{KOH}$}

$5 \mathrm{~g}$ of the prepared carbon of waste sago was added to $25 \mathrm{ml} \mathrm{KPH}$ solution, in varying percentage of 10, 15, $20 \%$. Each mixed solution was then boiled for 90 minutes to enhance the activation process and filtered. The activated product was then transferred to an oven and heated for an hour at $350^{\circ} \mathrm{C}$. After heating, the activated waste sago carbon was repeatedly washed with warm distilled water $\left(70^{\circ} \mathrm{C}\right)$ until constant $\mathrm{pH}$ solution of 7 was reached. Finally, the activated carbon was dried in an oven at $110^{\circ} \mathrm{C}$ for $24 \mathrm{~h}$.

\subsection{Functional Group Identification}

The PerkinElmer spectrum IR 10.6.1 Fourier-transform infrared (FTIR) spectroscopy was used to investigate the functional groups contained in the activated carbon materials. The powdered samples were placed in a holder on the surface of the sample and evacuated. Before each measurement, the instrument was run to collect the background, which was then automatically subtracted from the sample spectrum. The infrared portion of the electromagnetic spectrum were performed in wave numbers between $500-4000 \mathrm{~cm}^{-}$ ${ }^{1}$ regions.

\section{Results and Discussions}

Figure 1 shows the FTIR spectrum from waste sago carbon activated using acid activating agent $\mathrm{H}_{3} \mathrm{PO}_{4}$ with impregnation ratio of 6:1, 9:1, and 12:1 respectively. Detail absorption peaks of functional group were listed in table 1 . The peak absorption numbers $3344.09 \mathrm{~cm}^{-1}$ (Fig. 1a), $3248.15 \mathrm{~cm}^{-1}$ (Fig. 1b) and $3215.63 \mathrm{~cm}^{-1}$ (Fig. 1c) referred to $\mathrm{OH}$ 
stretching bonds which indicates the presence of the $\mathrm{OH}$ hydroxyl functional group. From the results obtained, there was a decrease in the absorption peak, this was due to the decomposition of the hydroxyl group and adsorbed water. The large hydroxyl group indicates the presence of strong hydrogen bonds from the carboxylate or phenol. Moreover, the decrease in the absorption peak suggested as an indication of the formation of aromatic compounds which are the constituent elements of activated carbon (Allwar et al., 2015). In the FTIR wave spectrum of phosphoric acid activated carbon, an absorption peak appears with wave numbers of $1584.60 \mathrm{~cm}^{-1}$ (Fig. 1a), $1583.94 \mathrm{~cm}^{-1}$ (Fig. 1b) and $1572.87 \mathrm{~cm}^{-1}$ (Fig. 1c). The absorption peaks between $1675-1500 \mathrm{~cm}^{-1}$ indicated the presence of the $\mathrm{C}=\mathrm{C}$ group.

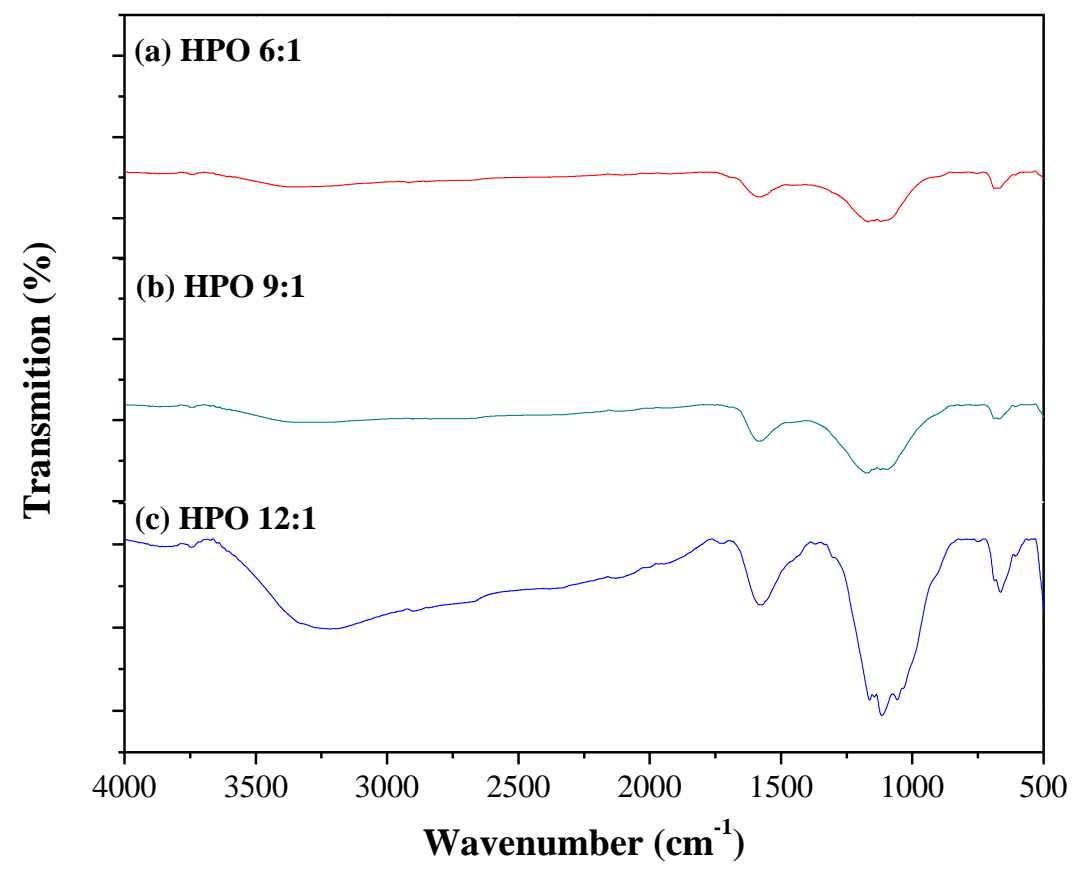

Figure 1. The FTIR spectrum from waste sago carbon activated using acid $\mathrm{H}_{3} \mathrm{PO}_{4}$ with impregnation ratio of (a) 6:1, (b) 9:1, and (c) 12:1.

Table 1. Absorption peaks of functional group from waste sago carbon activated using acid activating agent $\mathrm{H}_{3} \mathrm{PO}_{4}$

\begin{tabular}{ccccc}
\hline \multirow{2}{*}{$\begin{array}{c}\text { Functional } \\
\text { Groups }\end{array}$} & \multicolumn{3}{c}{ Wave Numbers $\left(\mathbf{c m}^{-\mathbf{1}}\right)$} & \multirow{2}{*}{ Compounds } \\
\cline { 2 - 4 } & HPO 6:1 & HPO 9:1 & HPO 12:1 & \\
\hline O-H & 3344.09 & 3248.15 & 3215.63 & Carboxylates, Phenols \\
\hline C=C & 1584.60 & 1583.94 & 1572.87 & Aromatic \\
\hline C-O & 1166.57 & 1171.91 & 1162.69 & Ether, Esters or Phenol \\
\hline C-H & 687.40 & 671.40 & 664.28 & Alkenes \\
\hline
\end{tabular}

Moreover, wave numbers of $1166.57 \mathrm{~cm}^{-1}$ (Fig. 1a), $1162.69 \mathrm{~cm}^{-1}$ (Fig. 1b) and $1171.91 \mathrm{~cm}^{-1}$ (Fig. 1c) showed the stretched of C-O functional groups either from ether, ester or phenol as suggested (Ahmad et al., 2014; Rattanapan et al., 2017). This is also in accordance with the research of Doke and Khan (2017), who found that the C-O functional groups of ether and ester appeared at wave number at $1060-1319 \mathrm{~cm}^{-1}$. After 
the activation process using $\mathrm{H}_{3} \mathrm{PO}_{4}$, it can be seen that there were wave numbers seen at $1166.57 \mathrm{~cm}^{-1}$ (Fig. 1a), $1162.69 \mathrm{~cm}^{-1}$ (Fig. 1b) and $1171.91 \mathrm{~cm}^{-1}$ (Fig. 1c) which may show vibrations stretch from $\mathrm{P}=\mathrm{O}$ from the $\mathrm{P}-\mathrm{O}-\mathrm{C}$ aromatic group, the strain vibration associated with ionized $\mathrm{P}+-\mathrm{O}-$ or asymmetric vibration from POP (Khana et al., 2018). Whereas the absorption peak with wave numbers $687.40 \mathrm{~cm}^{-1}$ (Fig. 1a), $671.40 \mathrm{~cm}^{-1}$ (Fig. 1b) and $664.28 \mathrm{~cm}^{-1}$ (Fig. 1c) indicated the presence of C-H groups $\left(650-900 \mathrm{~cm}^{-1}\right)$ which suggested to indicate the presence of alkane compounds (Paviam 1979).

Figure 2 shows the FTIR spectrum from waste sago carbon activated using base $\mathrm{KOH}$ with varying concentration of 10,15 , and $20 \%$. Detail absorption peaks of functional group were listed in table 2 . The absorption peaks with wave numbers $11371.64 \mathrm{~cm}^{-1}$ (Fig. 2a), $1370.78 \mathrm{~cm}^{-1}$ (Fig. 2b) and $1377.08 \mathrm{~cm}^{-1}$ (Fig. 2c) indicated the presence of CH groups (3000-2850 $\left.\mathrm{cm}^{-1}\right)$ which indicated the presence of alkane compounds. In addition to that, the wave numbers of $1217.05 \mathrm{~cm}^{-1}$ (Fig. 2a) and $1217.58 \mathrm{~cm}^{-1}$ (Fig. 2b) have indicated that there were the stretched C-O functional group from ether, ester or phenol (Ahmad et al., 2014; Rattanapan et al., 2017). This is also in accordance with the research of Doke and Khan (2017) who found that the C-O functional groups of ether and ester appeared at wave numbers $1060-1319 \mathrm{~cm}^{-1}$. After the activation process with $\mathrm{KOH}$, it can be connected to $\mathrm{C}$ and $\mathrm{O}$ on the carbon surface (Danish \& Ahmad, 2018). During activation using $\mathrm{KOH}$, the $\mathrm{OK}$ group formed on the surface is transformed into an $\mathrm{OH}$ group on washing with water through an ion exchange reaction (Viswanathan et al., 2009).

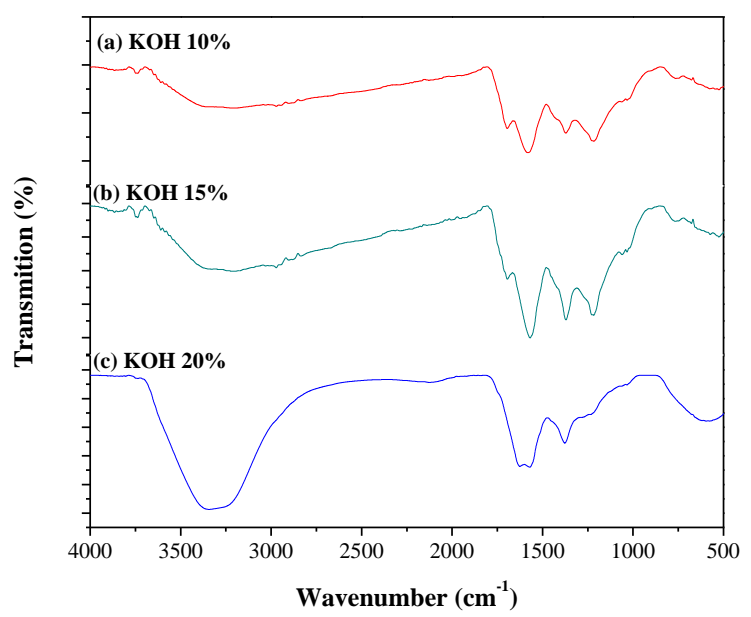

Figure 2. The FTIR spectrum from waste sago carbon activated using base activating agent $\mathrm{KOH}$ with varying concentration of (a) $10 \%$, (b) $15 \%$, and (c) $20 \%$.

Table 2. Absorption peaks of functional group from waste sago carbon activated using base activating agent $\mathrm{KOH}$

\begin{tabular}{|c|c|c|c|c|}
\hline \multirow{2}{*}{$\begin{array}{c}\text { Functional } \\
\text { Groups }\end{array}$} & \multicolumn{3}{|c|}{ Wave Numbers $\left(\mathrm{cm}^{-1}\right)$} & \multirow{2}{*}{ Compounds } \\
\hline & $\mathrm{KOH} 10 \%$ & $\mathrm{KOH} 15 \%$ & KOH $20 \%$ & \\
\hline O-H & 3342.19 & 3200.20 & 3199.55 & Carboxylates, Phenols \\
\hline $\mathrm{C} \equiv \mathrm{C}$ & - & - & 2128.44 & Alkyne \\
\hline $\mathrm{C}=\mathrm{C}$ & 1569.95 & 1569.21 & 1581,83 & Aromatic ring \\
\hline C-H & 1371.64 & 1370.78 & 1377.08 & Alkenes \\
\hline $\mathrm{C}-\mathrm{O}$ & 1217.35 & 1217.58 & - & Ether, Esters or Phenol \\
\hline
\end{tabular}


The presence of an increase in the functional groups on the waste sago activated carbon using $\mathrm{H}_{3} \mathrm{PO}_{4}$ and $\mathrm{KOH}$ can be used as an absorbent material. Activated carbon using $\mathrm{H}_{3} \mathrm{PO}_{4}$ in this study has the same functional group as the functional groups produced in Li et al. study ( $\mathrm{Li}$ et al., 2010). So that the activated carbon $\mathrm{H}_{3} \mathrm{PO}_{4}$ produced has the potential to remove lead (II) by adsorption in water. Meanwhile, the functional groups of $\mathrm{KOH}$ activated carbon obtained are the same as research conducted by Machida et al. (2012), which can be used effectively as adsorbents for the treatment of lead (II) and cadmium (II) aqueous wastewater.

\section{Conclusions}

The results of the identification of waste sago activated carbon functional groups from the Fourier-transform infrared spectrum showed that: waste sago activated carbon with activator $\mathrm{H}_{3} \mathrm{PO}_{4}$ in this study contained $\mathrm{OH}, \mathrm{C}=\mathrm{C}, \mathrm{CO}$ and $\mathrm{CH}$ functional groups which showed that the functional groups obtained were almost in accordance with the carbon standard structure active. Waste sago activated carbon with $\mathrm{KOH}$ activator in this study contained $\mathrm{O}-\mathrm{H}, \mathrm{C} \equiv \mathrm{C}, \mathrm{C}=\mathrm{C}, \mathrm{C}-\mathrm{O}$ and $\mathrm{C}-\mathrm{H}$ functional groups which also show that the functional groups conform to the standard structure of activated carbon. However, the activated carbon of waste sago with $20 \% \mathrm{KOH}$ activator identified the presence of $\mathrm{C} \equiv \mathrm{C}$ alkynes functional groups, along with the loss of the $\mathrm{C}-\mathrm{O}$ organic groups. The results of functional group identification provide recommendations for the development of the application of sago waste activated carbon made by activating $\mathrm{H}_{3} \mathrm{PO}_{4}$ and $\mathrm{KOH}$ as adsorbents in the purification of lead (II) and cadmium (II) wastewater.

\section{Acknowledgements}

This research was fully funded by the Ministry of Education and Culture of the Republic of Indonesia, through Fundamental Research of Higher Education Excellence (Penelitian Dasar Unggulan Perguruan Tinggi) Grant Year 2021.

\section{References}

Ahmad, M. A. N. A. A. Puad, O. S. Bello, Kinetic, (2014), "Equilibrium and thermodynamic studies of synthetic dye removal using pomegranate peel activated carbon prepared by microwave-induced $\mathrm{KOH}$ activation", Water Resour. Ind., vol. 6, pp. 18-35.s

Allo, Y. K. Sudarmono, and O. Togibasa, (2019), "Synthesis and Characterization of Activated Carbon from Sago Waste (Metroxylon sagu) with $\mathrm{ZnCl} 2$ Activation and HNO3 Modification. J. Idn. Chem. Soc., vol. 2, no.1, pp. 48-48.

Allwar, L.N. Sari, K. Merdekawati, and D. Rubiyanto, (2015), "Removal of Fe and Cu Ions from Patchouli Essential Oil Using ZnCl2-Activated Carbon Adsorbent Modified With Ammonia". IOSR-JAC. vol. 8, no. 2, pp. 17-23.

Alvarez, J. G. Lopez, M. Amutio, J. Bilbao, and M. Olazar, (2014), "Upgrading the rice husk char obtained by flash pyrolysis for the production of amorphous silica and high quality activated carbon”, Bioresour. Technol., vol. 170, pp.132-137.

Ansanay, Y. P. Kolar, R. Sharma-Shivappa, J. Cheng, and C. Arellano. (2021). 
"Pretreatment of Switchgrass for Production of Glucose via Sulfonic AcidImpregnated Activated Carbon”, Processes, vol. 9, no.3, p.504, 2021.

Bae, W. J. Kim, and J. Chung, (2014), "Production of granular activated carbon from food-processing wastes (walnut shells and jujube seeds) and its adsorptive properties", J. Air Waste Manage. Assoc., vol. 64, no. 8, pp. 879-886.

Başar, C. A. (2006), "Applicability of the various adsorption models of three dyes adsorption onto activated carbon prepared waste apricot”, J. Hazard. Mater., vol. 135, no. 1-3, pp. 232-241.

Bhatnagar, A. W. Hogland, M. Marques, and M. Sillanpää. (2013). “An overview of the modification methods of activated carbon for its water treatment applications", Chem. Eng. J., vol. 219, pp. 499-511.

Danish M. and T. Ahmad, (2018), "A review on utilization of wood biomass as a sustainable precursor for activated carbon production and application”, Renew. Sustain. Energy Rev., vol. 87, pp.1-21.

Dantas, T. L. P. F. M. T. Luna, I. J. Silva Jr., D. C. S. de Azevedo, C. A. Grande, A. E. Rodrigues, and R. F. P. M. Moreiraa. (2011). "Carbon dioxide-nitrogen separation through adsorption on activated carbon in a fixed bed", Chem. Eng. J., vol. 169, pp. 11-19.

Doke K. M. and E. M. Khan, (2017), "Equilibrium, kinetic and diffusion mechanism of $\mathrm{Cr}(\mathrm{VI})$ adsorption onto activated carbon derived from wood apple shell”, Arab. J. Chem., vol. 10, pp. S252-S260.

Faraji S. and F. N. Ani, (2015), "The development supercapacitor from activated carbon by electroless plating - A review”, Renew. Sustain. Energy Rev., vol. 42, pp. 823-834.

Foo K. Y. and B. H. Hameed. (2010). "An overview of dye removal via activated carbon adsorption process", Desalin. Water Treat., vol. 19, no. 1-3, pp. 255-274.

Foo, K. Y. and B. H. Hameed, (2012), "Coconut husk derived activated carbon via microwave induced activation: effects of activation agents, preparation parameters and adsorption performance". Chem. Eng. J. vol. 184, pp.57-65.

González-García. P. (2018). "Activated carbon from lignocellulosics precursors: A review of the synthesis methods, characterization techniques and applications," Renew. Sustain. Energy Rev., vol. 82, pp. 1393-1414.

Gupta, V. K. A. Nayak, S. Agarwal, and I. Tyagi, (2014), "Potential of activated carbon from waste rubber tire for the adsorption of phenolics: Effect of pre-treatment conditions", J. Colloid Interface Sci., vol. 417, pp. 420-430.

Ioannidou, O. A. and Zabaniotou, (2007), "Agricultural residues as precursors for activated carbon production - A review". Renew. Sustain. Energy Rev., vol. 11, no. 9, pp. 1966-2005.

Khana, E. A. Shahjahana, and T. A., (2018), “Adsorption of methyl red on activated carbon derived from custard apple (Annona squamosa) fruit shell: equilibrium isotherm and kinetic studies" J. Mol. Liq., vol. 249, pp. 1195-1211.

Kim, J. W. M. H. Sohn, D. S. Kim, S. M. Sohn, Y. S. Kwon, (2001), "Production of granular activated carbon from waste walnut shell and its adsorption 
characteristics for Cu2+ ion”, J. Hazard. Mater., vol. 85, no. 3, pp. 301-315.

Li, K. Z. Zheng, and Y. Li, (2010) "Characterization and lead adsorption properties of activated carbons prepared from cotton stalk by one-step H3PO4 activation", J. Hazard. Mater., vol. 181, no. 1-3, pp. 440-447.

Machida, M. B. Fotoohi, Y. Amamo, and L. Mercier, (2012), “Cadmium (II) and lead (II) adsorption onto hetero-atom functional mesoporous silica and activated carbon". Applied Surface Science, vol. 258, no.19, pp. 7389-7394.

Narowska, B. M. Kułażyński, M. Łukaszewicz, and E. Burchacka. (2019). "Use of activated carbons as catalyst supports for biodiesel production”, Renew. Energy, vol. 135, pp. 176-185.

Nor, N. M. L. L. Chung, L. K. Teong, and A. R. Mohamed, (2013), "Synthesis of activated carbon from lignocellulosic biomass and its applications in air pollution control - A review", J. Environ. Chem. Eng., vol. 1, no. 4, pp. 658-666.

Okada, K. N. Yamamoto, Y. Kameshima, and A. Yasumori, "Adsorption properties of activated carbon from waste newspaper prepared by chemical and physical activation”, J. Colloid Interface Sci., vol. 262, no. 1, pp. 194-199, 2003.

Pavia, L. D. (1979), Introduction To Spectroscopy: A Guide For Students Of Organic Chemistry, Philadelphia : Saunders College.

Rattanapan, S. J. Srikram, and P. Kongsune P, (2017), “Adsorption of methyl orange on coffee grounds activated carbon”, Energy Procedia, vol. 138, pp. 949-954.

Viswanathan, B. P. Indra Neel, and T. K. Varadarajan, (2009), Methods of Activation and Specific Applications of Carbon Materials. Chennai: National Centre for Catalysis Research, Indian Institute of Technology Madras.

Yagmur, E. M. Ozmak, and Z. Aktas, (2008), “A novel method for production of activated carbon from waste tea by chemical activation with microwave energy", Fuel, vol. 87, no. 15-16, pp. 3278-3285

Zhao, Y. F. Fang, H. M. Xiao, Q. P. Feng, L. Y. Xiong, and S. Y. Fu, (2015), "Preparation of pore-size controllable activated carbon fibers from bamboo fibers with superior performance for xenon storage", Chem. Eng. J. vol. 270, pp. 528-534, 2015.

Zhu, J. B. Shi, J. Zhu, and L. Chen, (2009), "Production, characterization and properties of chloridized mesoporous activated carbon from waste tyres", Waste Manag. Res., vol. 27 , no. 6 , pp. 553-560. 